\title{
Design of Tourism Cultural and Creative Products Based on Regional Historical and Cultural Elements
}

\author{
Yinglu $\mathrm{Wu}^{1 *}$ \\ ${ }^{1}$ Department of Art and Design, Guangzhou Institute of Technology, Guangzhou, Guangdong, 510000, China
}

\begin{abstract}
Regional historical culture is a special cultural system gradually formed after a long period of historical accumulation, which integrates regional cultural characteristics and spiritual connotations. Tourism cultural and creative products are high value-added industries in the tourism industry, and there is a lack of regional, historical and cultural element characteristics in some designs. Incorporating historical and cultural elements into the design of cultural and creative products, combining regional tourism resources with cultural and creative design, and imparting regional era characteristics to tourism projects, can promote the development of tourism, cultural and creative design industry and tourism economy. How to use regional historical and cultural elements in the design of tourism cultural and creative products has become an important research content of tourism cultural and creative product design. In this paper, the design of tourism cultural and creative products is the research content, using field research, questionnaire survey, analytic hierarchy and other methods, based on regional historical and cultural elements, to explore the design methods of tourism cultural and creative products.
\end{abstract}

\section{Introduction}

Regional culture refers to the cultural connotation with regional characteristics within a region containing material and spiritual characteristics, including the development patterns and social lifestyles of the place in different periods, as well as the unique cultural heritage and material heritage [1]. Looking at the world, many developed countries will choose cultural and creative industries that represent the direction of industrial development as the pillars of national economic development. China's tourism industry is developing rapidly. The total tourism revenue in 2019 will account for about one-tenth of the total GDP. The development of the huge tourism market provides unlimited opportunities for the development of the cultural and creative industry. In the report of the 19th National Congress of the Communist Party of China, it was pointed out that we must promote the development of cultural undertakings and cultural industries, and that the development of cultural industries requires new ideas and new ideas [2]. Both the Eleventh Five-Year Plan and the Twelfth Five-Year Plan mention the country's strategy for the development of the cultural industry, and the innovative design of regional tourism, cultural and creative products for cultural industries has risen to an important position in the national economy. For the research of tourism cultural and creative products, the main domestic examples are the Taipei National Palace Museum and Beijing's Forbidden City. The development of tourism cultural and creative products in tourist attractions and museums has begun, but relatively speaking, the new innovation model is not mature enough to be fully applicable to all [3].

\section{Regional Culture and Product Design of Tourism Cultural and Creative Products}

\subsection{Regional Culture}

The original meaning of culture refers to the cultivation and training of human abilities to make it above the natural state. Culture in the period of agricultural civilization refers to farming and cultivation of plants. With the development of social economy, culture is gradually cited as moral qualities. Regional culture refers to the cultural connotation with regional characteristics within a region containing material and spiritual characteristics, including the development form and social lifestyle of the place in different periods, as well as the unique cultural heritage and material heritage [4]. From natural resources and humanistic resources, a kind of cultural characteristics that can reflect national characteristics, thoughts, concepts, customs, beliefs, morals, ethics, etc., are collected, including hundreds of scholars, piano, chess, calligraphy, literature, drama, festivals, folk houses, Architecture, characters, languages, costumes, stories, characters, customs, dialects, singing and dancing, food, traditional Chinese medicine, religion, belief, philosophy, crafts, martial arts, etc., various regional cultures constitute China's extensive and profound national culture [5]. Formed a cultural characteristic that no country in the 
world can match. The Yangtze River culture and the Yellow River culture are the most representative and influential cultural matrix of Chinese civilization. The special physical and human geography of the Yangtze River Basin and the Yellow River Basin affect the overall cultural characteristics of this basin area; The farming culture and fishing and hunting culture of the Yangtze River culture, the farming culture and the nomadic culture of the Yellow River culture, the differences in soil and climate have formed a cultural situation with commonality and unique characteristics. For the study of regional culture, we must understand its historical, regional and cultural background and characteristics [6].

Fujian Tulou with typical regional residential culture is shown in Fig. 1.

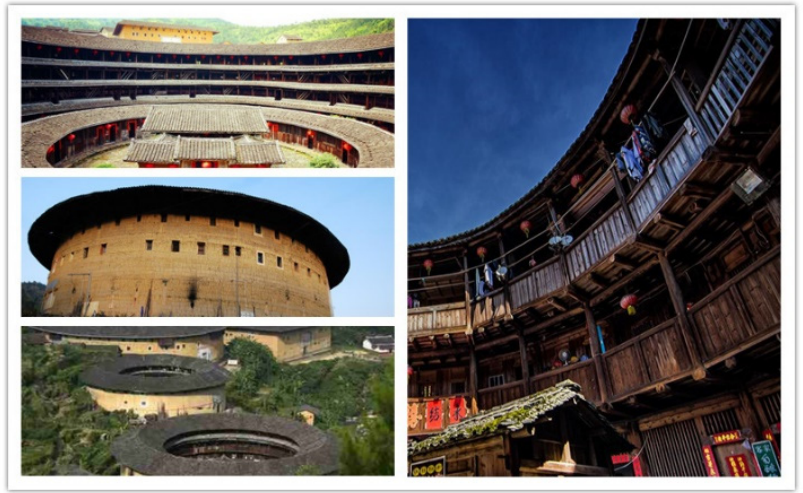

Fig 1. Fujian Tulou on the southeast coast of China

The Miao "Diaojiaolou" located in the southeast and southwest of Guizhou Province has also become a highlight of tourism culture due to its unique characteristics, as shown in Fig. 2.

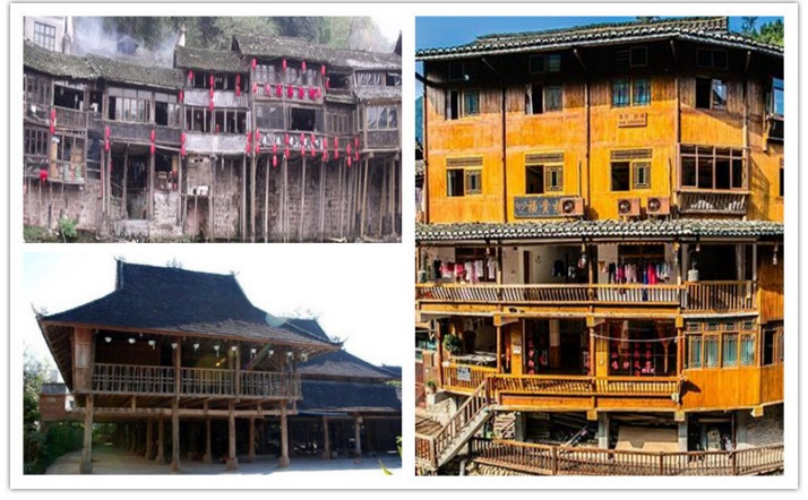

Fig 2. Diaojiaolou in Guizhou, China

\subsection{Overview of Tourism Cultural and Creative Products}

Broadly speaking, as long as it is a creative and meaningful item that carries the travel memory of tourists, it can be called a tourism cultural and creative product.

The rapid development of China's tourism industry, the gradual differentiation of the tourism market, and the emergence of a new cultural tourism model. According to data from the National Bureau of Statistics, the number of visitors to various cultural institutions such as museums, art galleries, and libraries in China is gradually increasing, and consumption. The demand for tourism cultural and creative products is also increasing, and many cultural institutions have begun the development of cultural and creative derivatives. In terms of meaning, tourism cultural and creative products are designed based on elements of regional cultural characteristics and represent the cultural and historical characteristics of a region [7].

The combination of tourism and culture has better highlighted the cultural nature of the scenic area, so that the scenic area is no longer a monotonous landscape experience. In the tourism industry chain, tourism cultural and creative products have been ignored by the industry. The rapid development of the tourism industry has made the same tourism products. The current performance of the tourism cultural and creative market is not very satisfactory. With the continuous improvement of people's lives, products that demonstrate individuality have gradually become the mainstream of consumption. With the continuous improvement of people's lives, products that demonstrate individuality have gradually become the mainstream of consumption.

\section{Tourism Cultural and Creative Product Design}

Tourism cultural and creative design needs to be combined with specific tourist attractions. In the implementation of cultural creative design, it will be affected by factors such as the regional and cultural characteristics of specific tourist attractions. In the process of design, in order to give tourist attractions the characteristics of the development of the modern era, the sense of innovation is also a necessary factor in the practice of cultural and creative design [8].

\subsection{Design Methods of Tourism Cultural and Creative Products}

Graphical design of historical and cultural symbols and architectural modeling. Many regional historical buildings have been passed on for thousands of years, and in terms of architectural structure and architectural modeling, they contain regional historical classical cultural heritage. In addition, many regional historical classical buildings and archaized representative buildings are beautiful in shape and rich in historical and classical cultural connotations. In tourism cultural and creative products, small objects printed with various regional historical special architectural graphics or ancient architectural shapes are often seen. product. Graphical design of regional historical architecture is one of the common design methods in the design of tourism cultural and creative products.

The design of modern tourism cultural and creative products based on regional historical and cultural elements must integrate regional historical traditional culture and modern craftsmanship, and refine and summarize regional historical traditional cultural symbols to create interesting tourist product shapes. In some historical cities, there are many positive traditional historical and cultural elements and symbols that can be used in the refinement and application of modeling. Through abstraction extraction and design, new developments in the symbolic modeling 
of tourism cultural and creative products can be given.

In terms of pattern design performance, through design methods such as segmentation, reorganization, and symmetry, diversified specific design presentation effects are designed, enriching the types of tourism cultural and creative products, and enhancing the attractiveness of products brought by the design. The use of segmented design expression techniques increases the abstraction of tourism cultural and creative design; the reorganized design expression method can enrich the expression form of tourism cultural and creative design. Within a limited range of materials, through segmentation and reorganization, different design schemes can be formed to increase the richness of tourism cultural and creative design; the symmetrical design expression method is quite satisfactory, giving people a sense of stability and peace of mind, and also gives the tourism cultural and creative design a symmetrical beauty. In the history and culture that have been passed down for thousands of years, each region has a variety of image patterns that give meaning to specific historical and cultural elements. For example, the auspicious cloud pattern symbolizes power and dignity, and the peony pattern symbolizes grace and luxury. The separation and re-arrangement and combination of the results give birth to a graphic with classical meaning but also rich in modern design features, so that graphic patterns with specific cultural meanings will be renewed by the design of tourism cultural and creative products based on regional historical and cultural elements machine [9].

The cartoonization of regional historical figures makes the original stereotyped historical figures more humorous, increases the interest of the design, and deepens people's impression of the character design. In order to improve the rationality of the cartoonization of historical figures, it is necessary to fully integrate with regional historical records, understand in advance the deeds and characteristics of regional historical figures, and after comprehensive consideration, determine the cartoon style positioning of historical figures, and use graphic design software to design the corresponding Historical cartoon character image. Historical figures, traditional patterns, and traditional architectural images contain classical culture that has been handed down for thousands of years, which is heavy and deep, but adds to the seriousness of traditional culture. Incorporating modern factors into the connotation of traditional culture, for example, the image of historical figures is linked to dance, yoga and other movements. The pattern is used for schoolbags or pillows, etc., which can enhance the commercial value of traditional culture and guide more people to interpret it.

\subsection{Design Ideas of Tourism Cultural and Creative Products}

The difference between the development essence of tourism cultural and creative products and the development of traditional products lies in the application of regional historical and cultural elements. The process of designing and developing a new tourism cultural and creative product is roughly divided into three stages: the collection and sorting of cultural elements, the creative design of products, and the production of products. Under the premise of integrating regional historical and cultural resources, accurately position the cultural and creative brand, and build it into the business card of regional historical and cultural brands through market-oriented operations. Through the creation of regional historical and cultural element names, it fully reflects the ideological core of regional historical culture.

Based on the product development process of regional historical and cultural elements, develop and design tourism cultural and creative products. The research and development of regional tourism cultural and creative products is the regeneration and utilization of historical and cultural elements, and the regeneration of general products is an improved design based on the original products. The regeneration of historical and cultural elements is a true process of processing innovation from scratch, which takes regional historical and cultural elements as the basic carrier of the product. Tourism cultural and creative products show abstract historical and cultural elements through new forms of expression, making it easier for people to accept and understand. Tourism cultural and creative products are based on historical and cultural elements, and the design process is divided into four stages.

\section{A Case Study of Tourism Cultural and Creative Product Design in Dunhuang Mogao Grottoes}

The essence of tourism cultural and creative products belongs to the category of tourist souvenirs in product design, and the design is based on local characteristics. The Dunhuang culture is different from the design of other cultural and creative products. The cultural elements of Dunhuang local attractions other than the Mogao Grottoes are relatively simple and easy to collect and organize. The culture of Mogao Grottoes is a collection that represents the culture of the past dynasties of China. Its murals and colored sculptures show not only Buddhist culture, but also the life scenes of the dynasty, costumes, houses, humanities and other elements. At the same time, Dunhuang is located in the northwest and is relatively rich in natural resources compared to other regions. Therefore, combining the Dunhuang culture and the particularity of the Dunhuang region, this article mainly cuts into the conceptual design from three aspects of product culture series, product materials, and lifestyle. Based on the core differences of each concept, it combines the corresponding cultural elements to form a tourism cultural creation. product.

The design method based on product culture series is mainly to explore the direct relationship between products and cultural elements. For Dunhuang cultural and creative products, they can be divided into grotto series, architectural landscape series, special product series, cultural relics history series, and each series uses pattern elements or a series design based on styling elements. Aiming at the Mogao Grottoes, the elements in the colored murals were extracted, re-drawn and designed. The 
Dunhuang pattern cultural and creative products are shown in Fig. 3.

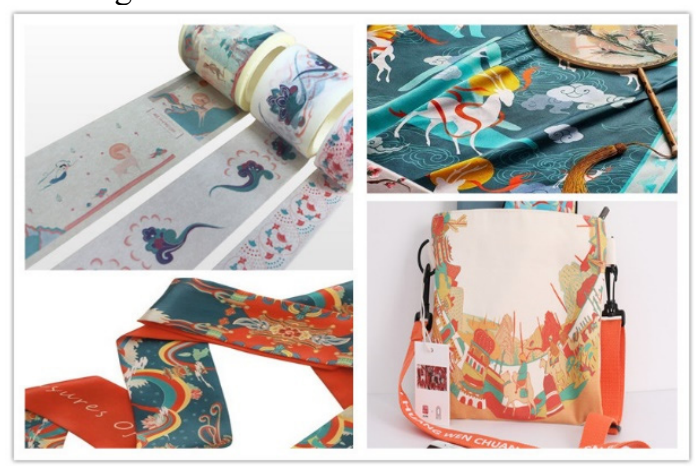

Fig 3. Dunhuang pattern cultural and creative products

Due to the historical reasons of Dunhuang architectural landscape, not many historical buildings are fully preserved. Based on the prototype of Mogao Grottoes, a series of cultural and creative products of architectural design are shown in Fig. 4.

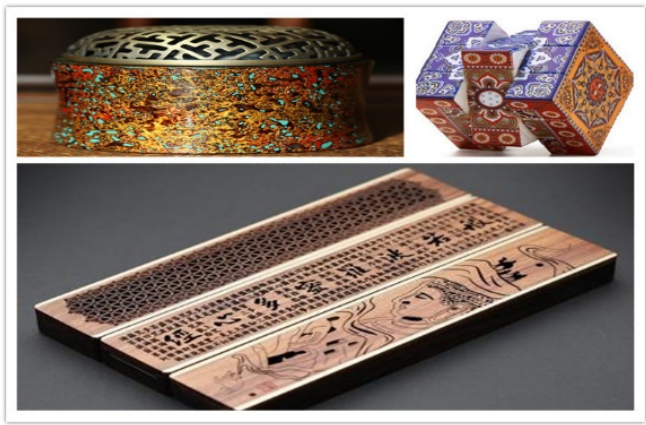

Fig 4. Dunhuang architectural tourism cultural and creative products

\section{Conclusions}

Based on the regional characteristic culture, it integrates various cultural creativity and modernizes the classic characteristic regional culture of tourism. The promotion and dissemination can further promote the prosperity and development of tourism, cultural and creative design, and effectively stimulate the value of regional history and culture in modern society. Based on the existing tourism advantages and historical resources of regional historical and cultural elements, and following the principles of cultural, regional and innovative principles, we make full use of the architectural styles in the ancient city, rich resources of historical figures, tile patterns and traditional color combinations, etc. Through cultural and creative symbolic modelling, structural reorganization of graphic patterns and graphic design of architectural modeling and other tourism cultural and creative design methods, injecting new era connotations into the traditional ancient city history and culture. Based on regional historical and cultural elements, this paper studies the design of tourism cultural and creative products. Taking the regional cultural guideline and Mogao Grottoes as a case, this paper analyzes the design of tourism cultural and creative products with historical and cultural elements in the Mogao Grottoes area.

\section{Acknowledgement}

This article is supported by the following fund projects. 2018 Academy-level Quality Engineering Project "Practice and Thinking on How to Carry Out Cultural Heritage Inheritance in Higher Vocational Design Education-Research on the Application of Cantonese Embroidery Design in Cultural and Creative Special Design Course", project number: YJG201816; Guangzhou Engineering Technology Vocational College 2017 "Innovative and Strong School Project" Skills Master Studio "Tan Zhanpeng-Huang Minjian Guang Embroidery Skills Master Studio", project number: ZYS201823.

\section{References}

1. H.Y. Yang. Research on the design of characteristic tourism cultural and creative products based on regional culture. Hubei University of Technology, (2016).

2. S.Y. Dong. Xibaipo Red Tourism Cultural and Creative Product Design Research. Beijing Institute of Graphic Communication, 2019.

3. W.L. Guo. Research on the design of tourism cultural and creative products based on Dunhuang culture. Xi'an Polytechnic University, (2018).

4. S.R. Zhou. Yandi tourism cultural and creative product design based on regional culture. Changsha University of Science and Technology, (2018).

5. K.D. Xue. Research on cultural and creative product design with regional cultural characteristics under the background of "tourism +" era. Southwest Jiaotong University, (2018).

6. C.F. Ma. Research on the Design and Development Strategies of Tourism Cultural and Creative Products_- Taking the Silk Road (Gansu Section) Tourism Cultural and Creative as an Example. China Packaging, 39(06): 86-88, (2019).

7. X.G. Zhao, H.X. Wang. Research on Suzhou Tourism Cultural Creative Product Design Application. Art and Design (Theory), 2(05): 85-87, (2020).

8. N.F. Bu. Research on the design of characteristic tourism cultural and creative products based on regional culture. Tomorrow's Fashion, (16):3-4, (2020).

9. H.X. Wang. Research on the design of Beijing tourism cultural and creative products. Beijing University of Architecture and Architecture, (2020). 